\title{
Metodologia de um Projeto de Extensão para Inclusão, Desmistificação e Empoderamento de Jovens Mulheres em Tecnologias da Informação e Comunicação
}

\author{
Helen Abdala R. Ferreira ${ }^{1}$, Alice F. Barbosa ${ }^{1}$, \\ Reinaldo B. Braga ${ }^{1}$, Marcia N. Viana ${ }^{1}$, Carina T. Oliveira ${ }^{1}$ \\ ${ }^{1}$ Laboratório de Redes de Computadores e Sistemas (LAR) \\ Instituto Federal de Educação, Ciência e Tecnologia do Ceará - Campus Aracati \\ Aracati - CE - Brasil \\ (helenabdala14, alice30feitosabarbosa) @gmail.com, \\ (marcia.viana, reinaldo.braga, carina.oliveira) difce.edu.br
}

\begin{abstract}
The Information and Communication Technologies (ICTs) grow in an accentuated way. However, although it's massive presence in most daily activities, digital inclusion is still a challenge in the current society, especially when it is related to the feminine public. In view of this problem, the present paper has the objective to describe a project methodology that focuses on the inclusion, desmistification and empowerment of women in the ICTs area. The methodology was applied with a group of young women from the Pedregal community, in Aracati-CE. The results obtained stand out the increase of services offered to socials segments with focus on the digital inclusion and the emancipation of the citizen.
\end{abstract}

Resumo. As Tecnologias da Informação e Comunicação (TICs) crescem de forma acentuada. Porém, apesar de sua presença cada vez mais massiva na maioria das atividades do cotidiano, a inclusão digital ainda é um desafio na sociedade atual, principalmente quando se trata do público feminino. Tendo em vista esta problemática, o presente artigo tem por objetivo descrever uma metodologia de projeto que visa incluir, desmistificar e empoderar a mulher na área de TICs. A metodologia foi aplicada com um grupo de jovens mulheres da comunidade do Pedregal, localizada em Aracati-CE. Os resultados obtidos destacam a elevação do índice de atendimento aos segmentos sociais com ênfase na inclusão digital e emancipação do cidadão.

\section{Introdução}

No decorrer dos últimos anos, vem ocorrendo um avanço exponencial em relação às Tecnologias da Informação e Comunicação (TICs). Tal progresso traz consigo novas oportunidades de aprendizado para propiciar uma vida mais fácil e agradável por meio de inovações tecnológicas [PINOCHET 2014]. Os autores dos trabalhos [DA SILVA 2012] e [RECUERO 2011] evidenciam que as TICs trouxeram inúmeras transformações para a sociedade, entre elas a conexão entre pessoas do mundo inteiro e a possibilidade de expressão individual ou coletiva. 
Nesse sentido, o conhecimento e utilização das TICs se tornaram algo indispensável, tanto para atender às necessidades do mercado de trabalho, quanto para atender às necessidades pessoais. No entanto, as TICs têm efeitos diversos e, apesar da sua presença cada vez mais massiva na maioria das atividades humanas, a denominada "exclusão digital" ainda está presente na sociedade atual. Este fenômeno atinge, principalmente, pessoas, organizações e países com baixos níveis de acesso às TICs, porém, este tema ainda é pouco debatido socialmente [BACH et al. 2013].

O desafio da inclusão digital é ainda maior quando se trata do público feminino. De acordo com um relatório da National Center for Women Information Technology (NCWIT), no ano de 2015 as mulheres representavam apenas 25\% das ocupações relacionadas à Ciência da Computação [ASHCRAFT and EGER 2016]. No Brasil, este cenário não é diferente, Maia [MAIA 2016] evidencia que a presença feminina nos cursos superiores brasileiros do campo da computação tem diminuído. O número de concluintes homens cresceu aproximadamente $98 \%$ entre 2000 e 2013, enquanto o número de concluintes mulheres decresceu em até $8 \%$ no mesmo período. Sobre os motivos que levam a esse cenário, o autor ainda sugere que determinados estereótipos podem dificultar a entrada de mulheres neste campo.

Diante das premissas expostas, reforça-se aqui a necessidade urgente de mais ações que permitam a inclusão, desmistificação e empoderamento da mulher em TIC. Pensando nisso, este artigo apresenta a metodologia e os resultados alcançados por um projeto de extensão de seis meses executado em 2017 por estudantes bolsistas e professores do curso de Bacharelado em Ciências da Computação do Instituto Federal de Educação, Ciência e Tecnologia do Ceará (IFCE) Campus Aracati. O projeto beneficiou um grupo de jovens mulheres que nunca havia entrado em contato com computadores. Dentre as etapas da metodologia, destacam-se a realização de um curso na área de TIC e atividades com jogos de tabuleiro para desenvolvimento do raciocínio lógico. O projeto elevou o índice de atendimento aos segmentos sociais com ênfase na inclusão digital e emancipação do cidadão.

\section{Metodologia do Projeto}

A metodologia de projeto proposta neste artigo foi implementada com sucesso na comunidade de Pedregal, localizada na cidade de Aracati-CE. Esta comunidade fica distante do centro da cidade; é composta, em sua maioria, por habitantes de baixa renda; e não oferece centros/escolas de informática na localidade.

A seguir, são descritas as cinco etapas do projeto, indicando o uso de materiais, métodos e/ou técnicas necessários para a sua execução.

\subsection{Etapa 1 - Organização e Montagem da Infraestrutura de Execução do Projeto}

A primeira etapa contemplou a organização e a montagem da infraestrutura de execução do projeto. A coordenação do projeto realizou uma seleção dos participantes com perfil para atuar no projeto. Dada a interdisciplinaridade do projeto, é desejável a participação de professores e alunos da área de TIC, assim como colaboradores de áreas como Pedagogia, Assistência Social, Psicologia, dentre outras.

Foi realizada uma reunião de kick-off para, em equipe, alinhar os requisitos, elaborar o plano de trabalho e estruturar o cronograma do projeto. Nesta etapa, a coordenação 
do projeto estreitou os laços com a Associação de Moradores do Pedregal (AMOP). Por fim, os alunos e professores do projeto deram suporte técnico em máquinas e outros equipamentos do laboratório de informática da AMOP para que o projeto fosse desenvolvido na comunidade. Ao todo foram reparadas cinco máquinas de um total de onze que não estavam em funcionamento. Foram disponibilizados notebooks do IFCE para auxiliar nas aulas.

\subsection{Etapa 2 - Delineamento do Perfil da Comunidade Atendida}

Foi aplicado um questionário (gerado no Google Forms) com o objetivo de delinear o perfil das mulheres atendidas. No total, oito mulheres foram beneficiadas pelo projeto. O tamanho da turma foi limitado pela capacidade do laboratório da AMOP. Obteve-se o seguinte perfil das alunas: faixa etária entre 25 e 40 anos; nenhuma possuía computador em casa; todas eram provenientes de escolas públicas e durante o período escolar não tiveram nenhum contato com computadores; sete das oito alunas possuíam filhos.

\subsection{Etapa 3 - Realização de curso na área de TIC}

O curso prático intitulado "Noções Básicas de Informática para Jovens Mulheres" foi realizado no laboratório de informática da AMOP no período de 08 de agosto a 26 de novembro de 2017. Ele teve uma duração de 20 horas/aula, com encontros realizados uma vez por semana no período da manhã, com duração de duas horas. O curso foi ministrado por estudantes bolsistas dos semestres iniciais do curso de Bacharelado em Ciência da Computação do IFCE Campus Aracati sob a supervisão dos professores do projeto. A Figura 1 apresenta algumas mulheres durante as aulas práticas no laboratório de informática da AMOP.

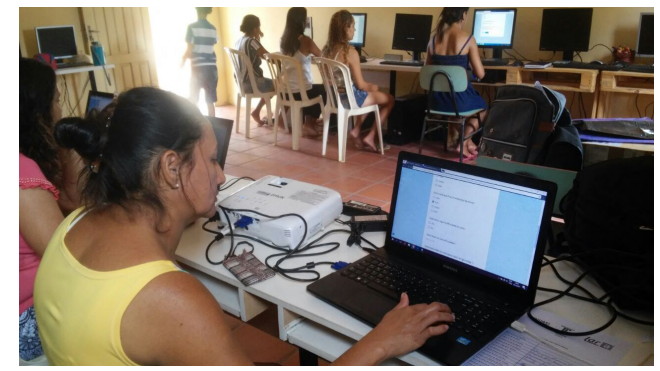

(a)

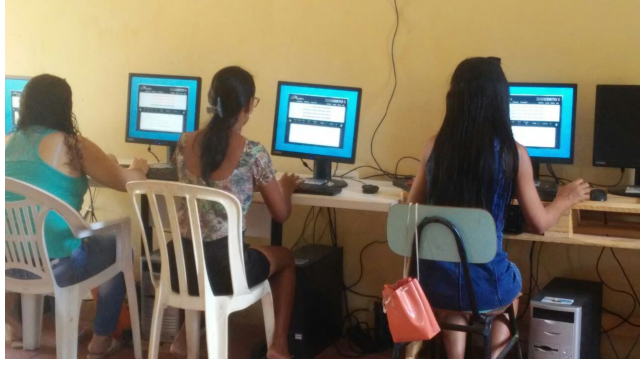

(b)

Figura 1. Atividades no laboratório de informática da AMOP em Aracati-CE.

O principal objetivo do curso foi garantir que a turma terminasse o mesmo sabendo manipular as funções básicas de um computador, desde ligar e desligar a máquina até navegar na Internet. Seguindo o plano de aula, foi proposto também o aprendizado de manipulações básicas de softwares de escritório, dentre eles os editores de texto, planilhas e apresentação.

\subsection{Etapa 4 - Atividade com Jogos de Tabuleiro}

Para complementar o curso de informática, foi proposta a utilização de jogos de tabuleiro como ferramenta para estimular a lógica computacional. Os jogos de tabuleiro, além de 
possuírem índole lúdica, são instrumentos que permitem estimular aspectos sociais, cognitivos e afetivos no participante, despertando o senso lógico e estratégico para a resolução de problemas [BRAGA 2018].

O jogo não só consiste em estimular a vontade de vencer com uma lógica de sucesso, mas também em fazer o aluno observar que o jogo pode influenciar em programações futuras [BARBOSA et al. 2017]. A partir do desenvolvimento de um bom raciocínio, análise de possíveis jogadas e soluções rápidas, contribuindo para a formação de um profissional qualificado.

\subsection{Etapa 5 - Encerramento do Projeto}

Nesta etapa ocorreu uma reunião de encerramento com as participantes do projeto para coletar lições aprendidas. Foi aplicado um questionário com as mulheres atendidas para avaliação do projeto. Além disso, foi realizada uma roda de conversa com os três estudantes bolsistas que atuaram no projeto. Os resultados do questionário e da roda de conversa são apresentados na próxima seção.

\section{Resultados}

Nesta seção, são apresentados os resultados do questionário aplicado com as alunas beneficiadas pelo projeto, além dos resultados da roda de conversa realizada com os três estudantes bolsistas do projeto. Os resultados obtidos no presente trabalho são referentes à primeira aplicação desta metodologia, sendo assim, os mesmos não puderam ser comparados a trabalhos anteriores.

Em relação às mulheres atendidas, $100 \%$ afirmaram ter aumentado o interesse em TICs e melhorado o crescimento profissional após a participação no projeto. Também foi perguntado como elas classificariam o curso. As respostas obtidas foram divididas entre: 2 acharam bom, enquanto 6 das mulheres consideraram o projeto ótimo. A metodologia aplicada foi considerada boa e eficiente pelas alunas concluintes.

Ao realizar uma roda de conversa com as mulheres atendidas pelo projeto, observouse que algumas sentiram dificuldades específicas durante o curso. A principal dificuldade listada pelas mulheres estava relacionada a fixação de alguns conteúdos, ocasionada pelo fato delas não possuírem computadores, o que as impedia de praticar algumas atividades propostas, como a datilografia. Contudo, as mulheres se mostraram persistentes e passaram a frequentar o laboratório em outros horários fora do curso, na intenção de colocar em prática os exercícios propostos.

Em se tratando dos estudantes bolsistas do IFCE Campus Aracati, percebeu-se que o projeto colaborou com o crescimento acadêmico e humano dos mesmos. Todos se mostraram visivelmente mais engajados com o curso, com os projetos de pesquisa e extensão do eixo e, finalmente, com a própria instituição. "Foi uma experiência interessante e diferente. Aplicar meus conhecimentos para ajudar outras pessoas me motiva mais a aprender, para melhorar ainda mais os projetos e ações", disse uma das bolsistas.

\section{Conclusões}

Este artigo apresentou uma metodologia de projeto de extensão que permite a inclusão, a desmistificação e o empoderamento de jovens mulheres em TICs. A metodologia apresen- 
tada pode auxiliar professores, pesquisadores, instituições de educação ou financiadores interessados em realizar iniciativas semelhantes.

Como trabalhos futuros, pretende-se replicar o projeto em outras comunidades do município de Aracati e região que ainda são excluídas digitalmente. Consequentemente, pretende-se preencher lacunas históricas na oferta de uma educação tecnológica que chegue de modo igualitário a todas as regiões do Estado do Ceará.

\section{Agradecimentos}

Este trabalho é um resultado parcial do projeto DIVAS (DesenvolvImento de ações socioeducatiVas para inclusão, desmistificAção e empoderamento da mulher em tecnologiaS da informação e comunicação), financiado pelo edital PAPEX/IFCE/2017.

\section{Referências}

ASHCRAFT, C.; McLAIN, B. and EGER, E. (2016). Women in Tech: The Facts. Disponível em <https://www.ncwit.org/sites/default/ files/resources/ncwit_women-in-it_2016-full-report_ final-web06012016.pdf>.

BACH, M. P., ZOROJA, J., and VUKŠIĆ, V. B. (2013). Review of Corporate Digital Divide Research: A Decadal Analysis (2003-2012). International Journal of Information Systems and Project Management, 1(4):41-55.

BARBOSA, A.; FERREIRA, H., BRAGA, R., VIANA, M., and OLIVEIRA, C. (2017). Uma metodologia lúdica para despertar a aprendizagem computacional em ambiente escolar de nível fundamental. In XXII Conferência Internacional sobre Informática na Educação (TISE).

BRAGA, R.; LOURDES, M. (2018). Aprendizado da Lógica Computacional por Meio de Jogos de Tabuleiro. Trabalho de Conclusão de Curso de Especialização em Formação Pedagógica para a Docência na Educação Profissional e Tecnológica - IFCE.

DA SILVA, R. C.; DA SILVA, R. (2012). Mídia e racismo. ABPN.

MAIA, M. M. (2016). Limites de gênero e presença feminina nos cursos superiores brasileiros do campo da computação. Cadernos Pagu, pages 223-244.

PINOCHET, L. (2014). Tecnologia da Informação e Comunicação. Elsevier Brasil.

RECUERO, R. (2011). Redes Sociais na Internet. Sulina. 